\title{
NÍVEL DE DESIDRATAÇÃO APÓS TREINAMENTO DE CICLISMO INDOOR
}

\author{
DEHYDRATION LEVEL AFTER INDOOR CYCLING TRAINING \\ NIVEL DE DESHIDRATACIÓN DESPUÉS DE ENTRENAMIENTO DE CICLISMO INDOOR
}

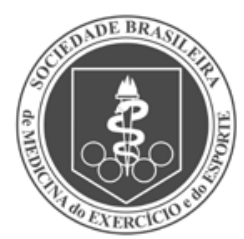

Artigo Original
Fernanda Nery ${ }^{1}$ (Educadora Física) Ana Paula Muniz Guttierres ${ }^{2}$ (Educadora Física)

Marcelo Ricardo Cabral Dias ${ }^{1,3}$ (Educador Físico)

1. Faculdade Metodista Granbery, Juiz de Fora, MG, Brasil.

2. Universidade do Estado do Rio de Janeiro, RJ, Brasil.

3. Universidade Trás-os-Montes e Alto Douro, Vila Real, Portugal.

\section{Correspondência:}

Marcelo Ricardo Cabral Dias. Rua Floriano Peixoto, 937 / 503

Centro, Juiz de Fora, MG, Brasil, 36015-360.diasmr@gmail.com

\section{RESUMO}

Introdução: A desidratação no ciclismo indoor é um tema pouco estudado na literatura. Objetivo: Verificar o nível de desidratação dos praticantes de ciclismo indoor após a atividade, assim como a presença de proteínas na urina. Métodos: Foram recrutados 30 homens ( $25,5 \pm 3,9$ anos), praticantes de ciclismo indoor, que realizaram um treinamento de 50 minutos de ciclismo indoor de característica intermitente: a) 5 minutos de aquecimento sem carga e com alta velocidade; b) 40 minutos de treinamento intermitente (alternando seis ciclos intensos de 5 minutos e cinco ciclos leves de 3 minutos); c) cinco minutos de volta à calma sem carga e com regressão da velocidade. Para a verificação do estado de hidratação, foram avaliados: massa corporal, desidratação relativa e absoluta, grau de desidratação, taxa de sudorese e densidade da urina. A intensidade do treino foi verificada por meio da frequência cardíaca e percepção subjetiva de esforço. Resultados: A perda de massa corporal após o treinamento foi significativa $(0,523 \pm 0,362 \mathrm{~kg})$ e correspondeu a um percentual de desidratação de 0,69 $\pm 0,47 \%$. Nenhum sujeito apresentou nível elevado de desidratação. Com relação à perda proteica na urina, $83,3 \%$ dos sujeitos apresentaram baixo nível de proteínas na urina, enquanto $16,7 \%$ apresentaram níveis moderados. Conclusão: A desidratação e a perda de proteínas na urina apresentaram baixos níveis após o treinamento de ciclismo indoor.

Palavras-chave: hidratação, proteinúria, sudorese.

\section{ABSTRACT}

Introduction: Dehydration in indoor cycling is an understudied topic in the literature. Objective: To determine the level of dehydration of practitioners of indoor cycling after activity, and the presence of protein in the urine. Methods: Thirty men ( $25.5 \pm 3.9$ years) indoor cycling practitioners who conducted a 50-minute intermittent training were recruited: a) 5 minutes of warm-up without load and high speed; b) 40 minutes of intermittent stimuli (six intense cycles of 5 minutes and five mild cycles of 3 minutes); c) 5 minutes of cool-down without load and with regression of speed. For checking the hydration status were evaluated: body mass, relative and absolute dehydration, degree of dehydration, sweating rate and density of urine. The training intensity was verified by heart rate and perceived exertion. Results: The body mass loss after training was significant $(0.523 \pm 0.362 \mathrm{~kg})$, corresponding to a percentage of dehydration of $0.69 \pm 0.47 \%$. No subject showed a serious level of dehydration. Concerning protein loss in the urine, 83.3\% of subjects had low levels, while 16.7\% showed moderate levels. Conclusion: Dehydration and loss of proteins in the urine showed low levels after training indoor cycling.

Keywords: hydration, proteinuria, sweating.

\section{RESUMEN}

Introducción: La deshidratación en ciclismo indoor es un tema poco estudiado en la literatura. Objetivo: Determinar el nivel de deshidratación después de la actividad de ciclismo indoor y la presencia de proteína en la orina. Métodos: Se reclutaron 30 hombres (25,5 $\pm 3,9$ años) con experiencia en ciclismo indoor realizaron un entrenamiento intermitente de 50 minutos: a) 5 minutos de calentamiento sin carga y alta velocidad; b) 40 minutos de estímulos intermitentes (seis ciclos intensos de 5 minutos y cinco ciclos suaves de 3 minutos); c) cinco minutos de enfriamiento sin carga y con regresión de la velocidad. Para evaluar el estado de hidratación se evaluaron: masa corporal, deshidratación relativa y absoluta, grado de deshidratación, tasa de sudoración y densidad de la orina. La intensidad del entrenamiento se constató por la frecuencia cardiaca y el esfuerzo percibido. Resultados: La pérdida de masa corporal después del entrenamiento fue significativa $(0,523 \pm 0,362 \mathrm{~kg})$, correspondiente a un porcentaje de deshidratación de 0,69 0,47\%. Ningún sujeto mostró un nivel grave de deshidratación. Con respecto a la pérdida de proteínas en la orina, el 83,3\% de los sujetos tenían niveles bajos, mientras que el 16,7\% tenían niveles moderados. Conclusión: La deshidratación y la pérdida de proteínas en la orina mostraron niveles bajos después del entrenamiento de ciclismo indoor.

Palabras clave: hidratación, proteinuria, sudoración. 


\section{INTRODUÇÃO}

O ciclismo indoor em academias se caracteriza por uma forma sistemática de treinamento em grupo em bicicletas estacionárias, que tem como principal finalidade o condicionamento cardiorrespiratório e o gasto calórico. A intensidade aplicada em uma bicicleta de ciclismo indoor é determinada pela potência mecânica (ou seja, cadência de pedalada $x$ deslocamento da roda) e carga resistiva'. Em todo o mundo o ciclismo indoor é um tipo de treinamento que possui um grande número de adeptos sendo, mais de 200.000 instrutores de ciclismo indoor foram

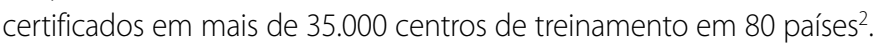

Alguns fatores do treinamento, como a intensidade do exercício', o nível de condicionamento dos praticantes, o tipo de atividade ${ }^{3}$ a alimentação e a ingestão de líquidos ${ }^{4,5}$ podem afetar o rendimento dos praticantes. As condições de uma atividade em um ambiente fechado, diminui a perda de calor por convecção e evaporação ${ }^{6}$. Brown e Banister demonstraram que ambientes fechados promovem um aumento de 36-38\% na taxa de suor. Nesta condição, o desequilíbrio da ingestão de líquidos é o principal fator de desidratação durante o exercício físico. Segundo o American College Sports Medicine - ACSM ${ }^{8}$, desidratação refere-se a perda de água do corpo. A quantidade de líquido perdida varia também conforme a temperatura ambiente e a intensidade do exercício 4 , a qual o desempenho no calor pode ser melhorado quando a quantidade de fluido adequado é ingerida ${ }^{5,9}$. Durante as aulas de ciclismo indoor, os sujeitos ingerem líquidos de forma ad libitum (ou seja, à vontade), além de poder ser estimulada em momentos específicos pelo treinador.

Comumente, é observado que praticantes de diferentes tipos de atividade física iniciam um exercício físico em déficit de líquidos, apresentando um estado hipoidratado, que indica níveis de líquidos insuficientes para manter a hidratação durante a prática do exercício ${ }^{5}$. Uma desidratação de $1 \%$ da massa corporal total tem um efeito mensurável sobre a resposta termorreguladora do exercício, enquanto um estado mais grave de desidratação (>6 a 7\% da massa corporal total) pode resultar em um evento fatal ${ }^{10}$. Quanto maior o déficit de água do corpo, maior será o aumento da tensão fisiológica devido aos aumentos da temperatura central, frequência cardíaca (FC) e percepção subjetiva de Esforço (PSE) durante o exercício ${ }^{11}$.

A FC e a PSE são parâmetros que indicam a sobrecarga de treino no ciclismo indoor 1,12. Há uma elevada correlação da FC e PSE com a intensidade que o exercício é realizado. O aumento da atividade simpática é responsável pelo incremento da FC durante o exercício, enquanto a PSE é considerada como um indicador do estresse físico, na qual são afetadas pelo estado de hidratação ${ }^{13}$.

Outro aspecto que pode ser afetado pelo nível de desidratação é a excreção de proteína por meio da urina (proteinúria). Existe uma relação do nível de proteinúria e o estado de hidratação do indivíduo, sendo que a presença de proteínas na urina tende a ser maior de acordo com o aumento do grau de desidratação ${ }^{14}$

Além disso, a densidade da urina tem sido considerada como um interessante método não invasivo para a avaliação do estado de hidratação dos atletas ${ }^{15}$. Segundo National Athletic Trainers' Association ${ }^{16}$, os valores para determinar o estado de hidratação segundo a densidade da urina são: hipohidratação = 21030; Euhidratados $=1013$ a 1029; Hiperhidratação = 1001 a 1012. No entanto, a densidade da urina não apresenta boa acurácia de forma isolada, visto que os resultados deste parâmetro devem ser combinados com resultados de outras variáveis como a perda da massa corporal e osmolaridade plasmática ${ }^{8}$.

Utilizando as palavras chave "indoor cycling", "spinning bike","spinning exercise", "sweat", "dehydration", "hyponatremia" e "hypohydration" nas bases de dados do PubMed (http://www.ncbi.nlm.nih.gov/pubmed) ob- servou apenas três trabalhos sobre a desidratação no ciclismo indoor, a qual justifica a importância do presente estudo. Desta forma, o objetivo foi verificar o nível de desidratação dos praticantes de ciclismo indoor após a atividade, assim como a presença de proteínas na urina.

\section{MATERIAIS E MÉTODOS}

\section{Sujeitos}

A amostra foi composta de 30 homens $(25,5 \pm 3,9$ anos, $1,75 \pm 0,05$ $m, 76,7 \pm 8,3 \mathrm{~kg}$ ), praticantes de ciclismo indoor com frequência mínima de duas sessões por semana a, pelo menos, seis meses de treinamento. Os sujeitos tiveram uma explicação prévia sobre os procedimentos do estudo e possíveis riscos, sendo que todos assinaram um termo de consentimento livre e esclarecido para a participação no mesmo. O estudo foi aprovado pelo Comitê de Ética em Pesquisas com Seres Humanos da Universidade Federal de Viçosa, MG, Brasil, conforme as normativas do CONEP, com número de registro 0139/2010.

\section{Procedimentos}

Os sujeitos foram submetidos a um treinamento de ciclismo indoor, de característica intermitente, com duração de 50 minutos assim divididos: a) cinco minutos de aquecimento sem carga e com alta velocidade (110 rotações por minuto - rpm); b) 40 minutos de treinamento intermitente (alternando seis ciclos de cinco minutos intensos a 80-90 rpm e cinco ciclos de três minutos fracos a 110 rpm); c) cinco minutos de volta a calma sem carga e com regressão da velocidade (de 110 a 50 rpm). A intensidade dos estímulos foi autosselecionada para que mantivessem a velocidade indicada. O treinamento aconteceu no período da noite, na qual a temperatura ambiente foi de $24,5^{\circ} \mathrm{C}$, medida por um termômetro de parede (Incoterm ${ }^{\circledR}$, TA35.05.0.00, Brasil) e a umidade relativa do ar permaneceu, em média, a 66\%, segundo a estação meteorológica da cidade (Juiz de Fora, MG, Brasil). A quantidade de água consumida foi de forma ad libitum, apesar de ser estimulada em momentos específicos pelo treinador. Ao final do treino foi analisada, individualmente, a sensação de náuseas ${ }^{17}$.

\section{Estado de hidratação}

Para a verificação do estado de hidratação dos sujeitos, foram avaliados os seguintes parâmetros: massa corporal, desidratação relativa e absoluta, grau de desidratação, taxa de sudorese e densidade da urina. Tais parâmetros foram avaliados conforme as descrições a seguir.

\section{Massa corporal, desidratação relativa e absoluta}

A massa corporal foi aferida utilizando uma balança mecânica (Filizola ${ }^{\circledR}$, São Paulo, Brasil), com acurácia de100 gramas. A massa corporal foi coletada antes $\left(M C_{\text {pré }}\right)$ e após a sessão de treinamento $\left(M C_{\text {pós }}\right)$, na qual foi utilizada para o cálculo da desidratação relativa e absoluta, taxa de sudorese e grau de desidratação.

O registro da massa corporal permitiu o acompanhamento da desidratação dos sujeitos de forma relativa (Equação 1) e absoluta (Equação 2), além de observar o percentual da perda hídrica representada pelo percentual de perda da massa corporal (\% MC). Assim, as equações utilizadas para acompanhar a desidratação foram às seguintes:

\begin{tabular}{|c|}
\hline Equação 1 - Desidratação Relativa $=M C_{\text {pré }}-M C_{\text {pós }}$ \\
\hline Equação 2 - Desidratação Absoluta $=\left(M C_{\text {pré }}+L i\right)-\left(M C_{\text {pós }}+U\right)$ \\
\hline
\end{tabular}

Onde: $\mathrm{MC}_{\text {pré }}=$ Massa corporal antes do treinamento; $\mathrm{MC}_{\text {pós }}=$ Massa corporal após o treinamento; $\mathrm{Li}=$ Líquidos ingeridos; $\mathrm{U}=$ Volume de urina produzido. 


\section{Taxa de sudorese}

A taxa de sudorese foi verificada pela Equação 3, proposta por Horswill18.

Equação $3-$ Taxa de sudorese $=\left[\left(M_{\text {pré }}-M C_{\text {pós }}\right)+L i-(U+F)\right] /$ tempo de exercício x 60 .

Onde: $\mathrm{MC}_{\text {pré }}=$ Massa corporal antes do treinamento; $\mathrm{MC}_{\text {pós }}=$ Massa corporal após o treinamento; $\mathrm{Li}=$ Líquidos ingeridos; $U$ = Volume de urina produzido; $F=$ Volume fecal produzido.

\section{Grau de desidratação}

O grau de desidratação foi calculado através da Equação 4, proposta por Burke e Hawley ${ }^{19}$ :

Equação 4 - Grau de desidratação $\left.=\left[\left(M C_{\text {pré }}-M C_{\text {pós }}\right)-U\right] / M C_{\text {pré }}\right] \times 100$

Onde: $\mathrm{MC}_{\text {pré }}=$ Massa corporal antes do treinamento; $\mathrm{MC}_{\text {pós }}=$ Massa corporal após o treinamento; $U$ = Volume de urina produzido.

\section{Densidade da urina e perda de proteínas}

A quantidade total de urina foi coletada antes e após o treinamento em bolsa coletora com capacidade de $300 \mathrm{~mL}$, na qual sua densidade foi determinada por um refratômetro óptico (LF Equipamentos ${ }^{\circledR}$, modelo 107/3, São Paulo, Brasil), calibrado com água deionizada. A densidade da urina foi utilizada como marcador do estado de hidratação. Para a mensuração da perda proteica na urina foram utilizadas fitas colorimétricas (Labtest Diagnostica S.A. ${ }^{\circledR}$, Lagoa Santa, Brasil).

\section{Frequência cardíaca e Percepção Subjetiva de Esforço}

A cada cinco minutos de treinamento foram medidas a FC (Polar ${ }^{\circledR}, \mathrm{FS} 1$, Finlândia) e a PSE (Escala de Borg 6-20), como parâmetros responsáveis por predizer a intensidade da sessão de treino de ciclismo indoor.

\section{Análise estatística}

Para verificar a distribuição da amostra foi realizado um teste de normalidade de Shapiro-Wilk e de homocedascidade de Levene. Como os dados apresentaram distribuição normal e homocedascidade, os resultados foram expressos através da média \pm desvio padrão. Para analisar as diferenças no percentual de perda da massa corporal, grau de desidratação, desidratação relativa e absoluta, taxa de sudorese, volume de urina e percentual de reposição foi utilizado um teste $t$ de Student pareado. As análises de correlação entre as variáveis foram feitas através da correlação de Pearson, e ainda, foi analisado a concordância das medidas de FC e PSE através do Coeficiente de Correlação Intraclasse (ICC). O nível de significância adotado foi de $p<0,05$. Os dados foram analisados pelo software SPSS 20.0 para Mac.

\section{RESULTADOS}

A intensidade do treinamento de ciclismo indoor foi acompanhada através da FC e PSE. A figura 1 apresenta o comportamento destas variáveis ao longo de 50 minutos do treinamento. Desta forma, foi verificado uma alta concordância entre as respostas médias tanto da FC, quanto da PSE (ICC =0,84).

A tabela 1 apresenta o balanço hídrico corporal resultante do treinamento de ciclismo indoor. A perda de massa corporal após o treinamento, corrigido pela reposição de água, foi significativamente diferente $(0,523 \pm 0,362 \mathrm{~kg}$; amplitude: 0,0-1,1 kg; $p>0,01)$ e correspondeu a um percentual de desidratação de 0,69 $\pm 0,47 \%$ (amplitude: 0,0-1,36\%). Os sujeitos reidrataram um equivalente de $72,7 \pm 23,3 \%$ (amplitude: 32,5-110,1\%) do total de líquido perdido.

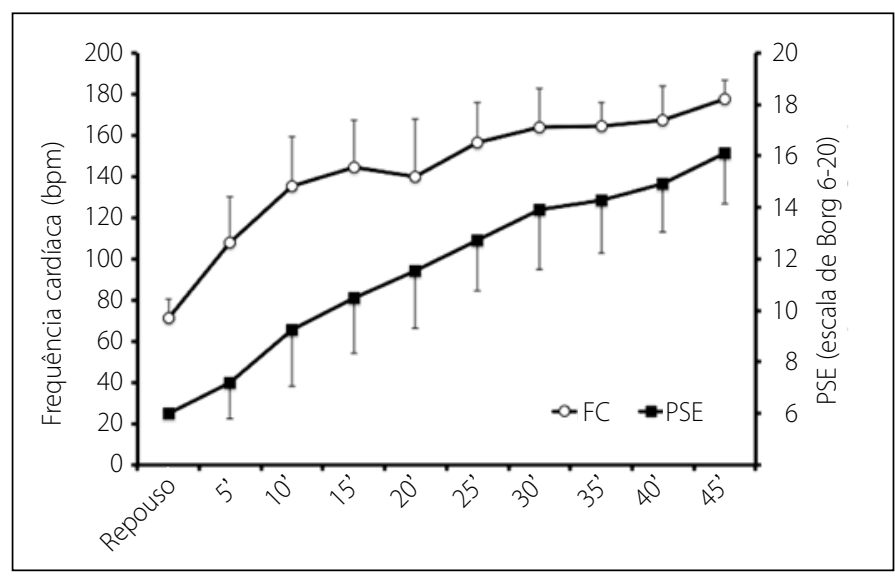

Figura 1. Comportamento da FC e da PSE ao longo do treinamento de ciclismo indoor.

Tabela 1. Balanço hídrico corporal da amostra $(n=30)$.

\begin{tabular}{c|c|c}
\hline Dados de desidratação & Média \pm Desvio padrão & Mínimo-máximo \\
\hline $\begin{array}{c}\text { Massa corporal } \\
\text { pré treino }(\mathrm{kg})\end{array}$ & $76,7 \pm 8,2$ & $56,9-98,2$ \\
\hline $\begin{array}{c}\text { Massa corporal } \\
\text { pós treino }(\mathrm{kg})\end{array}$ & $76,2 \pm 8,3^{*}$ & $56,8-98,3$ \\
\hline Desidratação absoluta $(\mathrm{kg})$ & $0,523 \pm 0,362$ & $0-1,1$ \\
\hline Desidratação percentual $(\%)$ & $0,69 \pm 0,47$ & $0-1,36$ \\
\hline Total de água ingerida $(\mathrm{mL})$ & $790,7 \pm 330,5$ & $200-1200$ \\
\hline Desidratação relativa $(\mathrm{kg})$ & $1,31 \pm 0,47$ & $0,6-2,2$ \\
\hline $\begin{array}{c}\text { Densidade da urina } \\
\text { pré treino }(\mathrm{mL})\end{array}$ & $1021,0 \pm 8,2$ & $1000-1030$ \\
\hline $\begin{array}{c}\text { Densidade da urina } \\
\text { pós treino }(\mathrm{mL})\end{array}$ & $1021,0 \pm 8,0$ & $1010-1030$ \\
\hline $\begin{array}{c}\text { Taxa de sudorese do } \\
\text { treinamento }(\mathrm{mL})\end{array}$ & $1342,3 \pm 496,9$ & $545-2150$ \\
\hline Grau de desidratação $(\%)$ & $0,63 \pm 0,49$ & $-0,07-1,30$ \\
\hline *Difereça significativam reça
\end{tabular}

* Diferença significativa em relação ao pré treino $(p<0,01)$.

Com base na coleta da urina realizada antes do treinamento, verificou-se que 16 sujeitos apresentaram desidratação mínima (1,010$1,020 \mathrm{~g} / \mathrm{mL}), 14$ apresentaram um nível de desidratação significativa (1,021-1,030 g/mL) e nenhum apresentou um nível de desidratação sério (> 1,030 g/mL). Após o treinamento, a distribuição do número de sujeitos foi de 17, 13 e zero, respectivamente para os níveis de desidratação mencionados anteriormente. A taxa de sudorese apresentou uma moderada correlação $(r=0,62 ; p=0,001)$ com a ingestão de líquidos.

A média da densidade da urina antes da treinamento foi de $1021,0 \pm 8,2 \mathrm{~g} / \mathrm{mL}$ (amplitude: 1000-1030 g/mL) e após foi de 1021,0 $\pm 8,0 \mathrm{~g} / \mathrm{mL}$ (amplitude: 1010-1030 g/mL). Não foi encontrada correlação entre a densidade da urina antes e após o treinamento e a quantidade de líquido ingerido ( $p=0,422$ e $p=0,270$, respectivamente). Da mesma forma, a correlação entre a perda da massa corporal e a densidade da urina após o treinamento não foi encontrada $(p=0,423)$. A tabela 2 indica a classificação do nível de hidratação de cada sujeito em relação ao percentual de diferença da $M C_{\text {pré }}$ e $M C_{\text {pós }}$ e a osmolaridade da urina.

Considerando a combinação dos resultados referente a densidade da urina e massa corporal, conforme estabelecido pelo NATA (Casa et al.) ${ }^{16}$, seis sujeitos (20\%) apresentaram desidratação mínima, enquanto 24 não se enquadraram nos critérios de classificação estipulado. Separadamente, conforme o \%MC, 18 sujeitos (60\%) apresentaram-se bem hidratados e 12 (40\%) com desidratação mínima. Já em relação a osmolaridade da urina, nenhum apresentou uma classificação de bem hidratado ou desidratação séria, 17 (56,7\%) com desidratação mínima e 13 (43,3\%) com desidratação significante. 
Tabela 2. Classificação do nível de hidratação em relação ao percentual de diferença da massa corporal e a osmolaridade da urina $(n=30)$.

\begin{tabular}{|c|c|c|c|}
\hline & $\% \mathrm{MC}$ & $\begin{array}{c}\text { Osmolaridade } \\
\text { da urina }\end{array}$ & Classificação* \\
\hline Indivíduo 1 & $-0,55$ & 1.030 & \# \\
\hline Indivíduo 2 & $-0,14$ & 1.030 & $\#$ \\
\hline Indivíduo 3 & $-0,29$ & 1.020 & \# \\
\hline Indivíduo 4 & $-1,10$ & 1.010 & $\begin{array}{c}\text { Desidratação } \\
\text { mínima }\end{array}$ \\
\hline Indivíduo 5 & $-0,86$ & 1.010 & $\#$ \\
\hline Indivíduo 6 & $-0,55$ & 1.020 & $\#$ \\
\hline Indivíduo 7 & $-0,00$ & 1.010 & $\#$ \\
\hline Indivíduo 8 & $-0,00$ & 1.010 & $\#$ \\
\hline Indivíduo 9 & $-0,37$ & 1.020 & $\#$ \\
\hline Indivíduo 10 & $-1,28$ & 1.025 & $\#$ \\
\hline Indivíduo 11 & $-0,55$ & 1.030 & $\#$ \\
\hline Indivíduo 12 & $-1,36$ & 1.020 & $\begin{array}{l}\text { Desidratação } \\
\text { mínima }\end{array}$ \\
\hline Indivíduo 13 & $-0,29$ & 1.030 & $\#$ \\
\hline Indivíduo 14 & $-1,03$ & 1.025 & $\#$ \\
\hline Indivíduo 15 & $-1,10$ & 1.020 & $\begin{array}{c}\text { Desidratação } \\
\text { mínima }\end{array}$ \\
\hline Indivíduo 16 & $-0,14$ & 1.020 & \# \\
\hline Indivíduo 17 & $-1,25$ & 1.030 & $\#$ \\
\hline Indivíduo 18 & $-0,51$ & 1.015 & $\#$ \\
\hline Indivíduo 19 & $-1,30$ & 1.030 & $\#$ \\
\hline Indivíduo 20 & $-1,30$ & 1.010 & $\begin{array}{c}\text { Desidratação } \\
\text { mínima }\end{array}$ \\
\hline Indivíduo 21 & $-0,37$ & 1.025 & $\#$ \\
\hline Indivíduo 22 & $-0,13$ & 1.010 & $\#$ \\
\hline Indivíduo 23 & $-1,10$ & 1.030 & $\#$ \\
\hline Indivíduo 24 & $-0,12$ & 1.010 & $\#$ \\
\hline Indivíduo 25 & $-0,37$ & 1.030 & \# \\
\hline Indivíduo 26 & $-0,18$ & 1.020 & $\#$ \\
\hline Indivíduo 27 & $-0,90$ & 1.030 & \# \\
\hline Indivíduo 28 & $-1,34$ & 1.010 & $\begin{array}{c}\text { Desidratação } \\
\text { mínima }\end{array}$ \\
\hline Indivíduo 29 & $-1,10$ & 1.020 & $\begin{array}{c}\text { Desidratação } \\
\text { mínima }\end{array}$ \\
\hline Indivíduo 30 & $-1,02$ & 1.030 & $\#$ \\
\hline
\end{tabular}

\%MC: Percentual de diferença da massa corporal; Osm.: Osmolaridade da urina. *National Athletic Trainers' Association16: Bem hidratado (\%MC $=+1$ a $-1 ;$ Osm. $=<1.010)$, Desidratação mínima (\%MC = -1 a $-3 ;$ Osm. $=$ 1.010-1.020), Desidrataçăo significante (\%MC $=-3$ a $-5 ;$ Osm. $=1.021-1.030)$ e Desidratação séria (\%MC $=>-5$; Osm. = > 1.030); \# Classificação não estabelecida

Em relação à perda proteica na urina, 83,3\% dos sujeitos apresentaram um baixo nível de proteínas na urina $(<30 \mu \mathrm{g} / \mathrm{dL})$, enquanto $16,7 \%$ apresentaram níveis moderados (30 $\mu \mathrm{g} / \mathrm{dL}$ ). Nenhum sujeito demonstrou vontade de urinar durante a treinamento. Vinte e nove sujeitos não sentiram nenhum grau de náuseas e, somente, 1 sentiu um leve grau de náusea logo após o treinamento de ciclismo indoor.

A taxa de suor durante o treinamento de ciclismo indoor apresentou uma correlação significativa $(r=0,62 ; p=0,002)$ com a ingestão de água, apresentado na figura 2. A FC se correlacionou com a PSE a cada cinco minutos de treinamento $(r=0,97 ; p<0,001)$ (figura 3). Além disso, a média da FC apresentou uma forte correlação com a densidade da urina antes e após o treinamento $(r=0,84 ; p<0,001)$.

\section{DISCUSSÃO}

No presente estudo, investigou-se o nível de desidratação após um treinamento de ciclismo indoor, assim como a presença de proteína na urina. Os sujeitos apresentaram uma perda significativa da massa corporal corrigida pela reposição de água $(0,523 \pm 0,362 \mathrm{~kg}$, correspondente a $0,69 \%$ da massa corporal total). A taxa de suor foi de

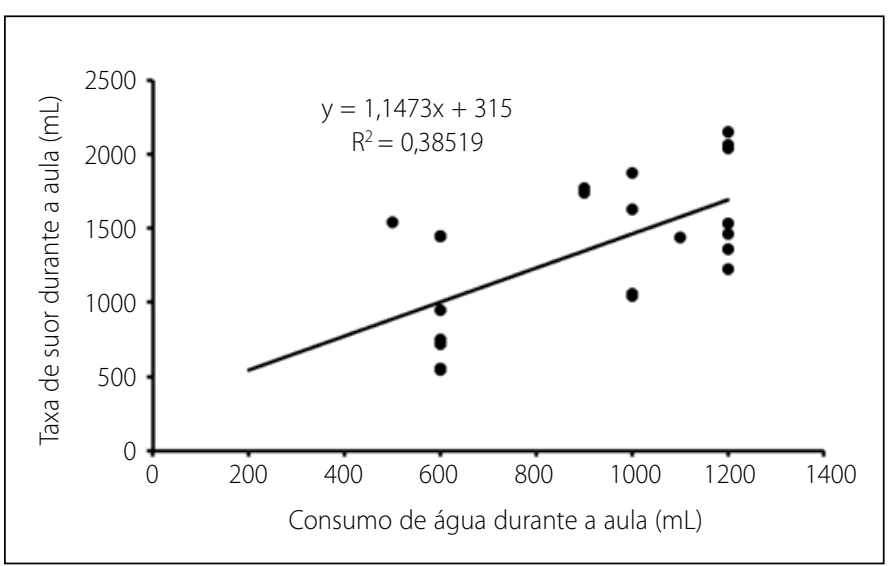

Figura 2. Correlação entre o consumo de água e a taxa de suor durante o treinamento de ciclismo indoor.

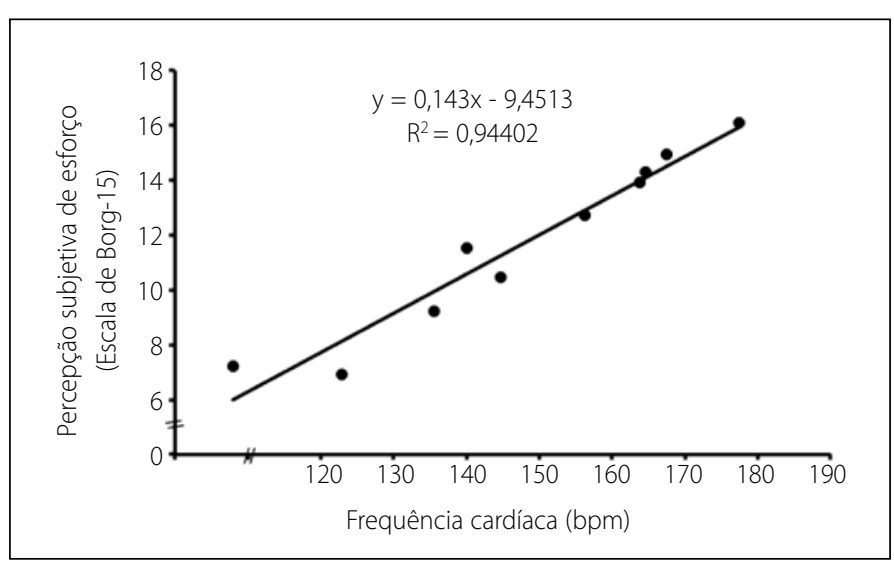

Figura 3. Correlação entre a FC e PSE durante o treinamento de ciclismo indoor.

1342,6 \pm 496,9 mL/treinamento com uma reposição hídrica de 790,7 $\mathrm{mL}$ durante (15,8 mL/min). Os praticantes reidrataram um equivalente a $72,7 \%$ do total de líquidos perdidos, que segundo Casa et al. ${ }^{4}$, quando a taxa de suor excede a ingestão de líquidos, significa que o indivíduo está desidratado. Da mesma forma, o estudo de Hazelhurst e Claassen ${ }^{20}$, com jogadores de futebol, mostrou que a ingestão de água ad libitum foi de 13,3 mL/min, que significou uma reposição de $68 \%$ das perdas hídricas. O valor de perda da massa corporal, no presente estudo, foi abaixo aos relatados por outros autores cuja variação ficou entre 1,4-2,2\% ${ }^{12,20}$. Talvez esta diferença possa ser explicada pelo fato da atividade de ciclismo indoor ser realizada em ambiente fechado e ventilado, o que pode proporcionar um menor estresse térmico. Com a facilidade de ingestão de líquidos e disponibilidade, a reposição líquidos foi na média já reportada no ciclismo indoor: $\pm 13,3 \mathrm{~mL} / \mathrm{min}$ $1200 \mathrm{~mL}$ de água ${ }^{20}$ e de $\pm 18,7 \mathrm{~mL} / \mathrm{min} 1679 \mathrm{~mL}$ de água alternada com fluídos carboidratados ${ }^{12}$. Com a necessidade de maior ingestão, pode se considerar um estado de hipohidratação voluntária, ou seja, quando o indivíduo tem disponibilidade de fluidos, porém acaba desidratando voluntariamente sem ingerir uma quantidade necessária. Isso pode ocorrer em ambientes de baixo estresse térmico, no qual fluidos com menor palatabilidade e baixo nível de sódio, como a água, estão disponíveis, no entanto, tais fluidos promovem um baixo estimulo à ingestão, promovendo uma hipohidratação voluntária, que é o caso do nosso estudo ${ }^{10}$.

Segundo o posicionamento do $A C S M^{8}$ em relação ao percentual de desidratação através da perda de água do corpo, quanto maior a perda de massa corporal maior é o nível de desidratação. Porém, uma desidratação com perdas abaixo de $2 \%$ da massa corporal, como no presente estudo, não degradam os níveis de força muscular e nem a 
performance anaeróbica. No estudo de Yamamoto et al. ${ }^{21}$, na execução de diferentes formas do agachamento com a barra por trás, a massa corporal diminuiu de 0,2 $\pm 0,4 \%$ a 4,8 \pm 0,4\%, conforme o estado de hidratação. Quanto menor era a ingestão de líquidos, maior foi o grau de desidratação. Porém, esta hipohidratação não promoveu diminuição da força muscular. Já em jogadores de futebol ${ }^{22}$, que ingeriram duas diferentes bebidas (bebida esportiva cafeinada e bebida caboidratada comercial) houve uma diminuição da massa corporal de 1,4 \pm 0,6\% e $1,0 \pm 0,6 \%$, respectivamente. Isso mostra que, além da quantidade de água ingerida, o tipo de bebida consumida promove diferenças nos níveis de desidratação.

Como neste estudo, os praticantes muitas vezes iniciam uma atividade física em estado de desidratação ou com uma quantidade quase normal de água no corpo e se desidratam ao longo de um período prolongado de exercício. Durante o treinamento, quando os intervalos entre os estímulos são inadequados, a reidratação pode se tornar um problema, que não aconteceu. Se a hidratação não for adequada, a desidratação aumenta a tensão fisiológica medida pela elevação da temperatura central e FC, embora cada fator seja único eles interagem degradando o desempenho do exercício ${ }^{11}$. Conforme a tabela 2, o nível de desidratação dos sujeitos. Assim, a indicação durante as aulas é que a ingestão contínua e lenta de líquidos é mais eficaz para a hidratação e reduz a produção de urina durante o exercício ${ }^{12}$.

Desta forma, a hidratação após os treinamentos é importante para que os sujeitos restabeleçam o balanço dos fluidos corporais, não permitindo a instalação de um quadro crônico de hipohidratação, ou seja, começar a atividade em estado de desidratação. A reidratação após o exercício deve ser concluída dentro de duas horas para procurar corrigir qualquer perda de líquidos acumulada durante a prática da atividade física. O principal objetivo da reidratação é o retorno das funções fisiológicas, no qual deve se ingerido água, para restaurar o estado de hidratação, e carboidratos, para repor o glicogênio e eletrólitos e acelerar a reidratação ${ }^{4}$.

No estudo de Guttierres et al. ${ }^{5}$, foi observado que após uma partida de futebol, o estado de desidratação dos jogadores tinha se agravado já que 17\% dos jogadores apresentaram uma séria condição de desidratação. No presente estudo, nenhum sujeito apresentou este estado de desidratação. Esta diferença pode ser explicada por diferentes fatores: o primeiro é o fato dos praticantes de ciclismo indoor terem iniciado a prática da atividade física em menor grau de hipohidratação; o segundo é que deve ser considerado o tempo total da atividade que os jogadores realizaram em 90 minutos de atividade contra 50 minutos de ciclismo; e por último, a diferença entre os tipos de atividade, o futebol com característica intermitente versus a característica cíclica do ciclismo indoor

Do pondo de vista mental e cognitivo existem algumas considerações: um dos efeitos deletérios de uma moderada ou severa desidratação é a redução na função cognitiva, na prontidão mental, no tempo de reação e no controle motor. No entanto, uma desidratação leve, definida como a perda de até 1 a $2 \%$ de massa corporal, não foi mostrado estar associado com decréscimos na função mental ou reação de tempo ${ }^{23}$. Entretanto, Edwards et al. ${ }^{24}$ avaliaram esta relação com perda de água de 1,5 a 2\% da massa corporal e constataram em prejuízos significativos no aspecto cognitivo geral, não prejudicando, especificamente, a concentração. A densidade da urina foi outro aspecto analisado no presente estudo, na qual não foi observada diferença entre antes e após a treinamento. Guttierres et al. ${ }^{5}$ encontraram uma densidade da urina, após um treinamento de futebol, maior que antes do treinamento (pré: $1023 \pm 6 \mathrm{~g} / \mathrm{mL}$; pós: $1027 \pm 6 \mathrm{~g} / \mathrm{mL}$ ). Isso mostra que os jogadores iniciaram o treinamento em maior estado de hipohidratação que os praticantes de ciclismo indoor (valor pré).
Os jogadores que apresentaram baixa perda de proteínas na urina ( $<30$ $\mu \mathrm{g} / \mathrm{dL}$ ) somaram $25 \%$, enquanto no presente estudo, $83,3 \%$. Em níveis moderados (30 $\mu \mathrm{g} / \mathrm{dL}$ ), os equivalentes foram de $30 \%$ dos jogadores e $16,7 \%$ dos praticantes de ciclismo indoor. Entretanto, nenhum praticante de ciclismo indoor apresentou níveis elevados de proteínas na urina (> $30 \mu \mathrm{g} / \mathrm{dL}$ ), já 30\% dos jogadores do estudo supracitado apresentaram.

Maiores níveis de proteína normalmente aparecem na urina após a realização de exercício extenuante, levando a uma maior proteinúria (perda excessiva de proteínas através da urina). Se os sujeitos se encontram em um estado hipohidratado, a proteína é excretada devido à diminuição do volume plasmático. A proteína presente na urina também acontece devido ao estresse causado pelo exercício e parece ser induzida por um aumento no sangue de ácidos, que levam a alterações na molécula de albumina ${ }^{14}$. Talvez a intensidade do treinamento de ciclismo indoor não tenha provocado um grande estresse fisiológico, pois a FC e a PSE apresentaram um comportamento em níveis moderados até 30-35 minutos de treinamento, só após este tempo apresentaram elevações significativas (FC: >85\%; PSE: >13).

No presente estudo, a média da FC durante o treinamento (132193 batimentos/minutos) foi similar aos apresentados na literatura ${ }^{12}$. De uma forma geral, tanto a FC quanto a PSE se comportaram com um aumento progressivo ao longo da atividade. Logo, maiores estresse orgânicos foram promovidos mais para o final da atividade. 0 aumento da desidratação ao longo da treinamento pode ser um dos fatores que contribuem para o aumento destes fatores ao longo do tempo. A desidratação aumenta a medida que a FC e PSE se elevam durante o estresse do esforço ${ }^{8}$. Isso deve acontecer até uns 50 minutos de exercício, pois a partir deste tempo parece que a FC e outros parâmetros cardiovasculares se mantém estáveis ${ }^{25}$. Entretanto, o nível de hidratação durante o treinamento pode minimizar as respostas elevadas da FC e da PSE.

Um fator que deve ser observado é o ambiente da prática da atividade, ou seja, a temperatura e a umidade relativa do ar dos treinamentos. No presente estudo, a temperatura ambiente permaneceu a $24,5^{\circ}$ e a umidade do ar a 66\%. Segundo Marino e Cannon ${ }^{9}$, a integridade do sistema neuromuscular é ajustada de acordo com o estado de hidratação e temperatura central. Neste estudo com ciclistas de rua, os autores verificaram o nível de desidratação não alterou a distância e nem o ritmo individual dos ciclistas. Como o treinamento de ciclismo foi realizado em um ambiente fechado e com ventilação, a influência ambiental foi minimizada, apesar de Ramos-Jiménez et al. ${ }^{12}$ não verificarem diferenças no desempenho mesmo em diferentes condições.

\section{CONCLUSÃO}

Os praticantes de ciclismo indoor envolvidos neste estudo apresentaram algum grau de desidratação antes do início da atividade, que poderia acarretar um possível estado de desidratação crônico ao longo da atividade. Após o treinamento, os praticantes apresentaram uma perda da massa corporal acarretado pelo grau de desidratação estabelecido durante o treinamento. O consumo de líquidos durante o treinamento foi abaixo que o esperado para o tempo de prática do treinamento. A maior parte dos praticantes $(83,3 \%)$ apresentaram baixo nível de proteínas na urina, enquanto $16,7 \%$ apresentaram níveis moderados.

A prática do ciclismo indoor já está estabelecida nas academias de atividade física. Porém, informações sobre as variáveis que influenciam o controle da intensidade do exercício, é fundamental para uma melhor prescrição do treinamento com segurança. Talvez seja recomendado a realização de novos estudos com o controle de diferentes quantidades de ingestão de líquido, para que seja possível ampliar a discussão sobre 
a quantidade de líquido e a forma de hidratação adequada durante um treinamento de ciclismo indoor. Apesar de não haver recomendações especificas, a ingestão ad libitum mostrou-se eficiente para este tipo de exercício com tempo inferior a uma hora de duração.

\section{AGRADECIMENTOS}

Os autores agradecem a CAPES e a Faculdade Metodista Granbery, Juiz de Fora, MG, Brasil, pelo amparo deste projeto e ao pro- fessor Dr. João Carlos Bouzas Marins por ter cedido parte dos equipamentos para a análise da urina.

Os autores agradecem a CAPES pelo fomento a pesquisa de projeto - protoc. BEX 0817/14-7

Todos os autores declararam não haver qualquer potencial conflito de interesses referente a este artigo.

\section{REFERÊNCIAS}

1. Dias MR, Lima JRP, Novaes JS. Cadência de pedalada no ciclismo: uma revisão de literatura. Motricidade. 2007,3(11):270-8.

2. Mad Dogg Athletics, Inc. [Internet]. Venice: About Mad Dogg Athletics, Inc. [07fev2014]. Disponível em http://www.spinning.com/en/about_mad_dogg_athletics.

3. American College Sports Medicine. Position Stand: Quantity and Quality of Exercise for Developing and Maintaining Cardiorespiratory, Musculoskeletal, and Neuromotor Fitness in Apparently Healthy Adults: Guidance for Prescribing Exercise. Med Sci Sports Exerc. 2011,43(7):1334-59.

4. Casa DJ, Clarkson PM, Roberts WO. American College of Sports Medicine roundtable on hydration and physical activity: Consensus Statements. Curr Sports Med Rep. 2005,4(3):115-27.

5. Guttierres APM, Natali AJ, Vianna JM, Reis VM, Marins JCB. Dehydration in soccer players after a match in the heat. Biol Sport. 2011,28(4):249-54.

6. Van Schuylenbergh R, Vanden Eynde B, Hespel P. Effects of air ventilation during stationary exercise testing. Eur J Appl Physiol. 2004,92(3):263-6.

7. Brown SL, Banister EW.Thermoregulation during prolonged actual and laboratory-stimulated bicycling. Eur J Appl Physiol Occup Physiol. 1985,54(1):125-30.

8. American College Sports Medicine. Position Stand: Exercise and Fluid Replacement. Med Sci Sports Exerc. 2007,39(2):377-90.

9. Marino FE, Cannon JD. Kay Neuromuscular responses to hydration in moderate to warm ambient conditions paced high during self- intensity exercise. Br J Sports Med. 2010,44(13):961-7.

10. Shirreffs SM. The optimal sports drink. Schweiz Z Med Traumatol. 2003,51(1):25-9.

11. Sawka MN, Coyle EF. Influence of body water and blood volume on thermoregulation and exercise performance in the heat. Exerc Sport Sci Rev. 1999,27:167-218.

12. Ramos-Jiménez A, Hernández-Torres RP, Wall-Medrano A, Torres-Durán PV, Juárez-Oropeza MA, Solis Ceballos JA. Physiological response during indoor cycling. Nutr Hosp. 2013,28(5):1487-93.

13. Arias MP, Díaz DP, Aristizabal JC, Jaramillo HN. Efeitos da desidratação, durante exercício submáximo de longa duração, na concentração sanguínea do lactato, na frequência cardíaca e na percepção subjetiva do esforço. Rev Bras Ciên e Mov. 2011,9(4):41-6.

14. Turgut G, Kaptanoglu G, Turgut S, Genç O, Tekinturkey S. Influence of acute exercise on urinary protein, creatinine, insulin like grown factor I (IGF-I) and IGF-I binding protein -3 concentrations in children. Tohoku J Exp Med. 2003,201(3):165-70.

15. Armstrong LE, Soto JAH, Hacker FT, Casa DJ, Kavouras SA, Maresh CM. Urinary indices during dehydration, exercise, andrehydration. Int J Sport Nutr. 1998,8(4):345-55.

16. Casa DJ, Armstrong LE, Hillman SK, Montain SJ, Reiff RV, Rich BS, et al. National athletic trainers' association position statement: fluid replacement for athletes. J Athl Train. 2000,35(2):212-24.

17. Murray R, Seifert JG, Eddy DE, Paul GL, Halaby GA. Carbohydrate feeding and exercise; effect of beverage carbohydrate content. Eur J Appl Physiol Occup Physiol. 1989,59(1-2):152-8.

18. Horswill CA. Effective fluid replacement. Int J Sport Nutr Exerc Metab. 1998,8(2):175-95.

19. Burke LM, Hawley JA. Fluid Balance in team sports: guidelines for optimal practices. J Sports Sci. 1997,24(1):38-54.

20. Hazelhurst LT, Claassen N. Gender differences in the sweat response during spinning exercise. J Strength Cond Res. 2006,20(3):723-4.

21. Yamamoto LM, Judelson DA, Farrell MJ, Lee EC, Armstrong LE, Casa DJ, et al. Effects of hydration state and resistance exercise on markers of muscle damage. J Strength Cond Res. 2008,22(5):1387-93.

22. Guttierres APM, Gatti K, Lima JRP, Natali AJ, Alfenas RCG. Efeito de bebida esportiva cafeinada sobre o estado de hidratação de jogadores de futebol. Rev Bras Ciênc Esporte. 2008,29(2):147-63.

23. Leibowitz HW, Abernethy CN, Buskirk ER, Bar-Or O, Hennessy RT. The effect of heat stress on reaction time to centrally and peripherally presented stimuli. Hum Factors. 1972,14(2):155-60.

24. Edwards AM, Mann ME, Marfell-Jones MJ, Rankin DM, Noakes TD, Shillington DP. The influence of moderate dehydration on soccer performance: Physiological responses to $45 \mathrm{~min}$ of outdoors match-play and the immediate subsequent performance of sport-specific and mental concentration tests. Br J Sports Med. 2007,41(6):385-91.

25. Miyai N, Arita M, Miyashita K, Morioka I, Shiraishi T, Nishio I. Blood pressure response to heart rate during exercise test and risk of future hypertension. Hypertension. 2002,39(3):761-6. 